\title{
SHIFTING VALUES IN INFORMATION TECHNOLOGIES
}

\author{
Phillip L. Davidson \\ CedarCreek Values Research Center and \\ The Fielding Institute \\ Santa Barbara, California \\ USA
}

\begin{abstract}
There has been a great deal of research since the turn of the century focused on the importance of values as they relate to human behaviour. This paper focuses on the dynamics of values in human behaviour and the ability to shift the emphasis of individuals from one set of values to another. This is done by first measuring shared group values. Once those values are known and areas of potential conflict noted, it might be possible to shift value emphasis to a set of shared values that are more in line with organisational goals and values. To validate this theoretical perspective, a five-year longitudinal study was conducted. The groups studied were part of an information systems implementation. Quantitative results of various value audits were compared across time. Results indicate that measurement of shared group values and an awareness of how values work can provide a mechanism for promoting a shift of values while diminishing or eliminating conflict.
\end{abstract}

\section{INTRODUCTION}

Beginning with the early work of Gordon Allport and Eduard Spranger, research has been conducted on the pivotal role of values in human behaviour (Allport \& Vernon 1931, Hall 1994, Rokeach 1973, Schwartz 1992, Spranger 1928). Studies focusing on conflict associated with information system implementations also demonstrate the central role that values can play in those conflicts (Macy 1995, Rezmierski 1992, Romm, Pliskin \& Weber 1995). Recent research suggests that knowledge of the specific values involved in these conflicts will allow organisations to shift away from traditional value-sets and focus on values that facilitate the management of system implementations (Davidson 1997a, DeGreene 1990). 
Managing system implementations is a common and complex task. More than $80 \%$ of such implementations are deemed as 'failures' (Heales 1995), based on cost overruns and extension of project time lines. The National Service Organisation (NSO) felt that many of the difficulties in project implementation had to do with conflict between their national information technology (IT) group-generally responsible for system implementations-and the various end user groups. There has been considerable documentation on this point (Bashein \& Markus 1997, Ross 1994, Santosus 1995). NSO decided to try and resolve this issue by utilising end users with technical skills, and have them take responsibility for system implementation. During the same time period, an attempt was made to determine the causes of conflict between IT and the end users.

\section{THE TEAM AND THE PROJECT}

One group of thirty individuals designated as a 'computer help desk (CHD)' was evaluated over a period of five years as part of the ongoing workplace study. The group was unique in that the individuals had technical computer skills but were drawn from the end user community rather than IT. A second group of eight IT professionals was also evaluated during the first phase of this study.

The history of the project can be broken into four distinct phases. The first year was spent in developing the computer database. The second phase was the implementation of equipment and training of staff at thirty remote offices. This second phase took approximately two years. The third phase was the establishment and refinement of the operational CHD. This phase lasted approximately twelve months. The fourth and last phase lasted approximately twelve months and was considered the maintenance phase. All outside offices were utilising the computer system by that time and the CHD had formalised both its internal structure and protocols. It was at the end of this period that responsibility for this function was transferred to another NSO location.

\section{METHOD}

The CHD group was evaluated in a number of ways during the five-year term of the project. Learning Skills Inventory (LSI) and Myers-Briggs Type Indicator (MBTI) tests were administered and results reviewed. The results 
of both indicated a significant degree of consistency among the group members. Both the CHD group and the IT support group were administered value audit surveys. The audit measures goal values - values an individual believes are ends in themselves. Both groups did so voluntarily. The IT group was not evaluated with the LSI or MBTI.

In the middle of the second phase (approximately two years after start-up), the CHD group was given a second values survey. Additionally, the value audit was administered one last time, approximately four and a half years after the start of the project and before the group became aware that CHD was going to be transitioned to another part of the country. This was six months into the maintenance phase of the CHD.

The theoretical basis behind the values audit tool comes from research that suggests values serve as strange attractors from the perspective of chaos theory (Davidson 1997a). Values are treated as physical entities that do not change in structure (Davidson 1997b), but can change in degree of expression within specific contexts. As such, they provide valuable information about organisational system dynamics.

\section{RESULTS}

The first values audit of the CHD was given to and voluntarily taken by 25 members of the computer help desk. There were 19 female and 6 male members. As a group, the values chosen are shown in Table 1.

Table 1. Values chosen and the number of times they were chosen by $C H D$

\begin{tabular}{|l|c|}
\hline \multicolumn{1}{|c|}{ Value } & $\begin{array}{c}\text { Number of } \\
\text { times chosen }\end{array}$ \\
\hline Work & 4 \\
Beliefs & 3 \\
Equality & 3 \\
Learning & 3 \\
Self Actualisation & 3 \\
Self Worth & 2 \\
Security & 2 \\
Wholeness & 2 \\
Confidence & 2 \\
\hline
\end{tabular}


The method of arrival at these responses was that all of the answers for each question were pooled. The values with the largest percentage of choices are those indicated above. The maximum number of times any value can be chosen is four.

In this first audit, it appeared that this was a very cohesive group, the majority of whom tended to define themselves by their work. While job and financial security did appear as an issue, it did not appear to be an overriding one. Since this group worked together for years with little change, that is probably understandable.

It is argued that values are consistent across cultures and genders. It is the expression of those values that change. Respondents to this survey did report gender and ethnicity, and the results showed slight shifts in emphasis based on culture and gender. It was of interest to track how value emphasis might change based on either gender or culture. Of particular interest were the five team members (one male, four females) born in Mainland China.

Women in the CHD group elected work as the most commonly selected value, and with a proportion slightly greater than the group as a whole. Men selected 'being self' at a higher rate than their female counterparts. Confidence was selected more frequently by the male members of the team, as well as valuing new organisational structure. Men and women both chose equality to the same degree, while female members chose wholeness slightly more than their male counterparts. Men tended to focus slightly more on security as a value then did women. Within those team members born in China, of those values with a clear majority, beliefs, family, and self-actualisation were the most frequently chosen.

The same values survey was also given in this time period to an eightperson IT team who were specifically designated to provide IT support for the CHD implementation. This group consisted of six males and two females. The result of their survey is shown in Table 2 . 
Table 2. Values chosen and the number of times they were chosen by IT support group

\begin{tabular}{|l|c|}
\hline \multicolumn{1}{|c|}{ Value } & $\begin{array}{c}\text { Number of } \\
\text { times chosen }\end{array}$ \\
\hline Work & 4 \\
Structure/Order & 4 \\
Learning & 3 \\
Security & 3 \\
Self Actualisation & 3 \\
Power/control & 2 \\
\hline
\end{tabular}

The second survey of the CHD group was conducted approximately one year after the first and approximately three years after project start-up . This was also at the beginning of the third phase. Implementation of the system had just been finished.

While there were no major changes, the increase in confidence, the importance placed on learning, and the individual focus on work did show small increases. Issues around security diminished slightly.

In the third survey, results were again very similar, although security began to increase $(8 \%)$, while beliefs and work showed small decreases. In all three surveys, work and learning were the highest values, with confidence, equality, and self-actualisation remaining close behind.

\section{CONCLUSIONS AND DISCUSSION}

The purpose of this research was to create a model that would provide better understanding of the dynamics of values within information technology, specifically within system implementations. Such a model might provide methods for shifting active ('espoused') values of the individuals involved and improve IT performance through the reduction of conflict.

The efficiency of an organisation is heavily influenced by shared group values. Values, as attractors in a complex dynamic system, are able to shape an organisation. This is a theory that has been long held within organisational psychology as witnessed by the use of vision and mission statements, management by objective, total quality management, and so on, 
which are all ways of shaping organisational behaviour based by what is important (what is of value).

The strength by which values are held is an important indicator. By using a values survey (audit), one gets some indication of value 'strength' if a respondent selects a value the maximum number of times. Methods of correlating the total number of values chosen and the absolute strength by which those values are held would also be helpful (the timing aspect of the new survey adds significantly to this point).

In this study, the initial structure of the CHD group suffered from a lack of clarity regarding what their new organisation would look like. While the lack of structure was of only moderate concern for the CHD group, it was a major value for the IT support team whose cultural bias towards control and structure was evident in the first value audit.

The issue of group structure for CHD was resolved by selecting a group of people with strong and consistent values around their work and their predilection for learning.This is an important aspect in trying to accomplish a shift in values. If the initial group could first be screened for those values that maximise the opportunity to achieve organisational goals, the process of implementation becomes much easier.

In the first value audit, both the CHD and the IT group choose 'work' the maximum number of times. This reflects current research that demonstrates how people - world-wide - increasingly define themselves through their work (Bumpus \& Munchus 1996, Crosby, Bitner \& Gill 1990, Super \& Sverko 1995). There was no conflict here. Clearly, both groups saw their work as extremely important.

It was also relevant to the CHD that each team member held a significant faith in his or her own competence. This was important because they were in a situation where people with weaker emphasis on confidence might not have remained because of a lack of structure. Their own values around work, learning, confidence, self-actualisation, and equality provided the values that served as the attractors that shaped the organisation over its five year history. It is suggested here, however, that if these values had been better known and promoted early in the project, the disquiet that existed while issues were being resolved would have been virtually non-existent. 


\subsection{Conflict}

The first conflict between CHD and the IT group appeared in the values chosen after 'work'. While the CHD group placed a strong emphasis on their belief systems as far as knowing the right thing to do, the IT group had a strong emphasis on structure and order. This emphasis on structure by the IT group, supported by their value on control (not seen in the CHD group), appeared to be at the core on the conflict between the IT group and the end users. Resolution of this conflict was difficult and was eventually resolved through an autocratic process of mandating that the end users would be the final deciding group as to issues of implementation.

Security, as a value, was more frequently chosen by the IT group than CHD. Part of that might be explained, however, due to a series of reorganisations taking place within the larger IT group during this process. Researchers have shown that threatening situations (such as possible job loss) will create a movement back towards more elemental values (Hall 1994, Maslow 1970).

\subsection{Dynamics}

Values provide a source of directed energy. The focus of the CHD group towards proving itself, as demonstrated in their strong value system, provided the momentum to accomplish a task that was considered impossible by most of the parent organisation. A project such as the CHD was anticipated to take ten years to implement using IT projections. The actual implementation was accomplished in three years and under budget.

The CHD project also demonstrated Kurt Lewin's field theory in that the momentum towards the end goal diminished as the team got closer to that goal (Lewin, 1951). Momentum came to a virtual standstill when the implementation was finished. Again, the momentum was an integral part of the values needed to accomplish the task (and thereby substantiating their individual values as knowledge workers). Once the task was finished, there was nothing left to prove, and energies turned inward.

So far, the description has been fairly linear, focusing on the values along the straight lines and containment noted by structure, direction, and momentum. The trajectory, however, was not so linear. Figure 1 gives a graphical representation of organisational dynamics of the $\mathrm{CHD}$ project. 


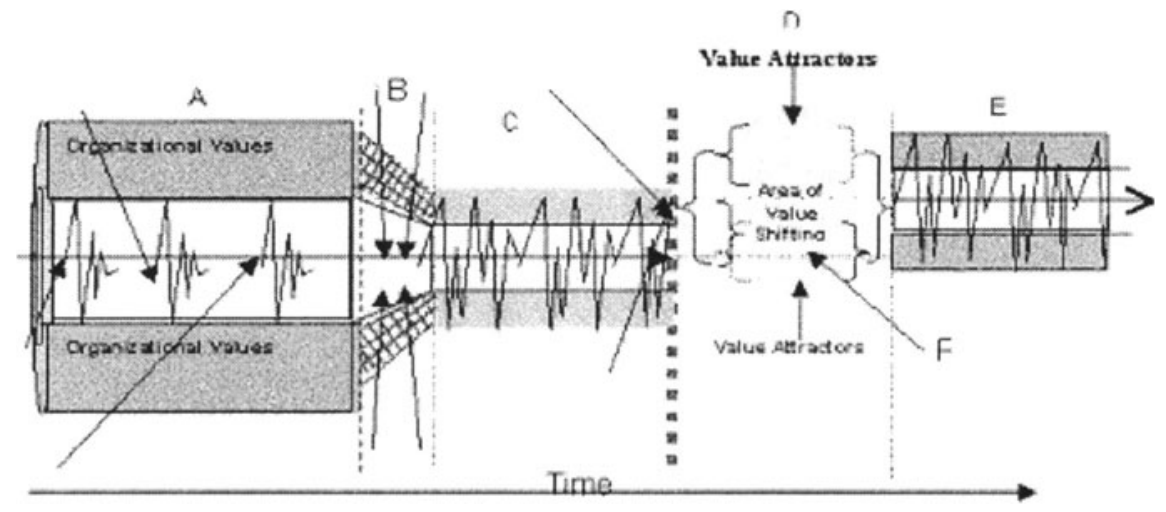

Stage A represents the near-to-equilibrium stage. For the CHD group, this would be the first year of the project. This was a time where stress was minimal; schedules were focused on learning skills based on database creation, transition management, and adult learning models. Contractor specialists who were not part of the CHD group taught each of these knowledge areas. Values that defined the project were an integral aspect of the individuals and the temporary project manager (who had hired the team).

The charter of the group was clear, and perturbations from external and internal stimuli were quickly dampened. The project momentum was on a 'fast track', per the organisational charter, and the direction was straight. There was also significant support from NSO that helped to dampen perturbations from other groups within NSO.

Stage B was a major transitionary phase in that the original project manager left the organisation and a new system manager was hired from outside NSO. Her values followed more 'traditional' IT lines. This more traditional structure emphasised segmented learning (called 'staging' in the IT world), so that no one knew the entire picture. This value was in direct conflict with the closely held CHD group value of shared learning but supportive of the IT values around structure and control. The change in managers and the value conflicts between the new manager and the group moved the group into stage $\mathrm{C}$, one of wide oscillations in behaviour and far-from-equilibrium. 
If one were using the values-based model suggested, the problems mentioned so far could have been avoided and the group would still be in a near-to-equilibrium status. By being aware of the initial groups' values necessary for the task at hand, one could have promoted those values actively and openly within the group and within the cultural icons of the group, and by making sure that the new manager's values were not in conflict with the groups'. Through use of the value auditing and interview, these issues could have been avoided.

The CHD group hit the interface between stages $\mathrm{C}$ and $\mathrm{D}$ approximately one and a half years into the project. The new manager resigned and the computer software demonstrated a lack of ability to handle the size of the project. This required multiple rapid actions. First, the implementation needed to continue as far as it could while a newer version of the software was tested - a six month effort. Second, a new manager had to be selected.

By this time, the values-mapping protocol had been tried once and was suggested as a possible tool in assisting with mediating this issue. A third manager was hired who was in strong compliance with the CHD's values. $\mathrm{He}$ was also a long-term employee of NSO and shared the organisational goals described for the CHD group.

By focusing on the issues of knowledge and learning and self-actualisation and work labour, and by making these prominent attractors to behaviour as the group moved through the dynamic phase $\mathrm{D}$, the group evolved into a different group. It was no longer a single-focused project team, but a versatile, knowledgeable, and flexible work team.

Use of this values auditing tool for adding predictability of the CHD group demonstrates that there is every reason to believe that the model is functional in a positive sense, both in the beginning of organisational development as well as for organisations undergoing dramatic, deep-level, organisational change. Foreknowledge of team-member shared values and value strengths can be a significant positive in system implementations.Having a common focus (not based on a feeling, but, rather, based on reproducible, quantitative date) should provide greater member job satisfaction as well as improving implementation performance. Both job satisfaction and improved performance should also reduce the overall expense of system implementation. The CHD project came in almost $\$ 14$ Million under budget, and began to realise a return on investment in less than four years. In addition, the implementation was accomplished on time. 


\section{FUTURE RESEARCH}

This presentation encompasses only a small portion of the actual work undertaken in this five-year study. A significant amount of qualitative research focusing on non-directed interviews was conducted in the middle of the five-year study. This research supports the findings of the quantitative study. Regardless, the findings cannot be considered conclusive. More groups need to be studied. The relationship between gender and ethnicity also provided slight variations in the overall data, and these relationships could also have a bearing on overall group success. Future work will examine these areas in greater detail.

\section{REFERENCES}

Allport, G. W., \& Vernon, P. E. (1931) A study of values: a scale for measuring the dominant interests in personality. Houghton Mifflin Company, Boston.

Bashein, B. J., \& Markus, M. L. (1997) A credibility equation for IT specialists. Sloan Management Review 38(4) 35-44.

Bumpus, M. A., \& Munchus, G. (1996) Values in the workplace: Diversity in meaning and importance. International Journal of Value-Based Management 9(2) 169-194.

Crosby, L. A., Bitner, M. J., \& Gill, J. D. (1990) Organisational structure of values. Journal of Business Research 20(2) 123-134.

Davidson, P. L. (1997a) A theoretical values-based model for parametric organisational destochastization. Unpublished Doctoral thesis, The Fielding Institute, Santa Barbara.

Davidson, P. L. (1997b) Values don't change: so now what? Paper presented at the Society for Research in Adult Development, Boston, CA.

DeGreene, K. B. (1990) The turbulent-field environment of sociotechnical systems: beyond metaphor. Behavioral Sciences 35(1) 49-59.

Hall, B. P. (1994) Values shift: a guide to personal and organizational transformation. Twin Lights Publishers, Inc, Rockport.

Heales, J. (1995) Measuring the organizational cultural influence on ISD. Department of Commerce, The University of Queensland, via the Internet, pp. 1-4.

Lewin, K. (1951) Field theory in social science. Harper \& Brothers, New York.

Macy, G. (1995) The role of values in implementing progressive organizational practices. International Journal of Value-Based Management 8(1) 39-51. 
Maslow, A. H. (1970) Motivation and personality. (Third ed.). Harper Collins, New York.

Rezmierski, V. E. (1992) Managing information technology issues of ethics and values: awareness, ownership, and values clarification. Cause/Effect 15(3) 12-19.

Rokeach, M. (1973) The nature of human values. The Free Press, New York.

Romm, C. T., Pliskin, N., \& Weber, Y. (1995) The relevance of organizational culture to the implementation of human resources information systems. Asia Pacific Journal of Human Resources 33(2) 63-80.

Ross, M. H. (1994) The culture of conflict. The American Political Science Review 88 p.789.

Santosus, M. (1995) Sharing power safely. $C I O$ (February 15, 1995) 50-58.

Schwartz, S. (1992) Universals in the content and structure of values: theoretical advances and empirical tests in 20 countries. In Zanna, M. (ed.) Advances in Experimental Social Psychology, Vol. 25, Academic Press, Orlando, pp. 1-65.

Spranger, E. (1928) Types of men. Niemeyer, Halle.

Super, D. E., \& Sverko, B. (eds.). (1995) Life roles, values, and careers: international findings of the work importance study. Jossey-Bass Publishers, San Francisco. 